\title{
Variations in the Configuration of the Celiac Trunk Among South Africans: Clinical Relevance
}

\author{
Variaciones en la Configuración del Tronco Celíaco en Sudafricanos: Relevancia Clínica
}

\author{
Diana Pillay ${ }^{1}$; Shaun Dieter Nischk ${ }^{1} \&$ Robert Ndou $^{2}$
}

PILLAY, D.; NISCHK, S. D.\& NDOU, R. Variations in the configuration of the celiac trunk among South Africans: Clinical relevance. Int. J. Morphol., 38(6):1662-1667, 2020.

SUMMARY: The celiac trunk is the first major unpaired branch of the abdominal aorta found at the twelfth vertebral level (T12). It gives off branches supplying the spleen, liver and the stomach. However, the branching patterns of the celiac trunk tend to vary by population throughout the world. We sought to investigate the branching patterns of the celiac trunk in a South African Caucasian sample. The celiac trunk was assessed by visual observation in 66 dissected bodies comprised of both males $(n=30)$ and females $(n=36)$. These samples were obtained at the School of Anatomical Sciences, University of the Witwatersrand, Johannesburg. The celiac trunk arose directly from the abdominal aorta in all cases, with none connected to the superior mesenteric artery. We observed celiac trunk trifurcation in $84.84 \%$ of the sample, although a celiac trunk with four branches was observed in $10.61 \%$. Bifurcation into the common hepatic and splenic arteries forming a hepatosplenic trunk ( 2 females) or into the left gastric artery and splenic artery forming a splenogastric trunk (1 male) was also observed. The results are largely comparable with other studies in Caucasians, showing a high rate of celiac trunk trifurcation (above $75 \%$ ). Our sample exhibited fewer variations than reported in previous studies worldwide. Therefore, a larger study with more samples may be required in the future to ascertain all the existing celiac trunk branching patterns in the South African Caucasian population.

KEY WORDS: Celiac trunk; Splenogastric; Hepatosplenic; Abdominal aorta; Superior mesenteric.

\section{INTRODUCTION}

The celiac trunk is found on the ventral aspect of the aorta, below the diaphragmatic aortic hiatus. It is the first major visceral artery to branch from the abdominal aorta. This short blood vessel originates at the level between the twelfth thoracic (T12) and first lumbar vertebra (L1). It gives off branches that supply the liver, gallbladder, stomach, pancreas and spleen (Moore et al., 2014). The branches are the common hepatic artery (CHA), left gastric artery (LGA) and splenic artery (SA). However, variations in the configuration, length and diameter of the celiac trunk and its main branches often occur. The latest description of celiac trunk branching patterns was by Panagouli et al. (2013), and more recently, by Pinal-Garcia et al. (2018) (Table I).

The nomenclature of the variations depends on the configuration of the branches to the liver, gallbladder, stomach, pancreas and spleen. The configuration is a tripod if the left gastric artery (LGA), common hepatic artery (CHA) and splenic artery (SA) arise directly from the celiac trunk $(\mathrm{CT})$. This is further divided into a true or false tripod depending on the position of the branches relative to the trunk. A true tripod is considered when all these three branches arise at the terminal aspect of the trunk whereas it is a false tripod if there is a branch arising on the stem of the trunk before its terminal portion (Fig. 1a \& b). Other variations in configuration include a splenogastric trunk in which the common hepatic artery arises from the abdominal aorta (Fig. 1c). In some cases, it is the left gastric artery arising directly from the aorta (Fig. 1d). Several classifications of the celiac truck branching patterns have been reviewed by Panagouli et al., who also suggested a more comprehensive categorisation (Table I) that was recently adopted by Pinal-Garcia et al.

Cases exhibiting hexafurcation and heptafurcation have also been described in other studies (Pinal-Garcia et al.) whereas some have reported a missing celiac trunk (Fahmy \& Sadek, 2015). In the latter, the left gastric, hepatic and splenic arteries each have a separate origin directly from the aorta. The knowledge, recognition and awareness of

\footnotetext{
${ }^{1}$ School of Anatomical Sciences, Faculty of Health Sciences, University of the Witwatersrand, Johannesburg, 7 York Road, Parktown, 2193 , South Africa. ${ }^{2}$ Department of Anatomy and Histology, School of Medicine, Sefako Makgatho Health Sciences University, Ga-Rankuwa, Pretoria, 0204, South Africa.
} 
Table I. A summary of the celiac trunk branching patterns. CT, Celiac trunk; CHA, common hepatic artery; LGA, Left gastric artery; SA, Splenic artery; SMA, superior mesenteric artery; AA, abdominal aorta. Adopted from (Panagouli et al.; Pinal-Garcia et al.).

\begin{tabular}{|c|c|c|}
\hline Type & Subtype & Description \\
\hline \multirow[t]{6}{*}{ I } & & Trifurcation of the CT into LGA, CHA and SA \\
\hline & 1 & True tripod - LGA, CHA and SA share a common \\
\hline & 2 & False tripod - division into two branches \\
\hline & $2 \mathrm{a}$ & The LGA is the first branch \\
\hline & $2 b$ & The CHA is the first branch \\
\hline & $2 \mathrm{c}$ & The SA is the first branch \\
\hline \multirow[t]{10}{*}{ II } & & Bifurcation of the CT \\
\hline & 1 & Hepatosplenic trunk, LGA arising from the AA \\
\hline & 2 & Hepatosplenic trunk, no normal LGA \\
\hline & 3 & Hepatosplenic trunk, and gastromesenteric trunk \\
\hline & 4 & Splenogastric trunk, CHA arising from the AA \\
\hline & 5 & Splenogastric trunk, CHA arising from the SMA \\
\hline & 6 & Splenogastric trunk and hepatomesenteric trunk \\
\hline & 7 & Hepatogastric trunk, SA arising from the AA \\
\hline & 8 & Hepatogastric trunk, SA arising from the SMA \\
\hline & 9 & Hepatogastric trunk and splenomesenteric trunk \\
\hline III & & Additional branches \\
\hline IV & & Celiac-mesenteric trunk (CT and SMA) \\
\hline $\mathrm{V}$ & & Variations in the origin of the $\mathrm{CHA}$ \\
\hline VI & & Hepatosplenomesenteric trunk, LGA arising independently or as a branch \\
\hline VII & & Absence of the CT (LGA, CHA and SA arising independently) \\
\hline VIII & & Splenogastromesenter ic trunk, CHA arising independently or as a branch \\
\hline IX & & Splenogastric trunk giving rise to a common inferior phrenic trunk \\
\hline $\mathrm{X}$ & & Celiac-bimesenteric trunk (CT, SMA and IMA) \\
\hline
\end{tabular}

celiac trunk configuration and branching pattern variations plays an important role in preoperative planning and in minimising postoperative complications (Koops et al., 2004).

Celiac trunk variations have been studied and reported in American (Lipshutz, 1917), Japanese (Chen et al., 2009), Korean (Song et al., 2010), Indian (Prakash et al., 2012), and Greek (Venieratos et al., 2013) cadaveric samples, however, no such reports exist for a sample of South African cadaveric specimens. Therefore, the primary aim of this study was to document and report on the number and frequency of celiac trunk variations seen in a South African cadaveric sample. The clinical relevance of these variations is also put into perspective.

\section{MATERIAL AND METHOD}
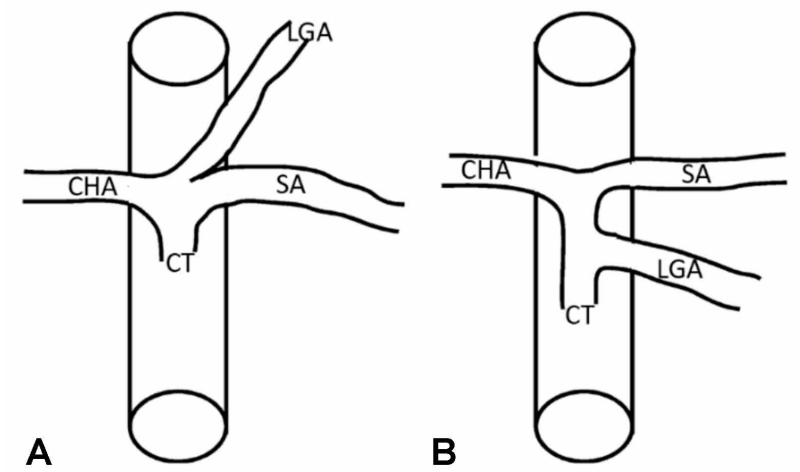

C

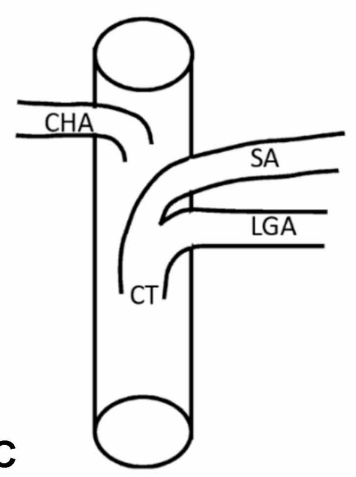

Study design. Ethics for the study falls under the ethics waiver (W-CJ-140604-1) granted by the University of the Witwatersrand Human Research Ethics Committee in respect of the Human Tissue Act No. 65 of 1983 and the National Health Act No. 61 of 2003 (of South Africa) that make provision for use of cadaveric material for research purposes. The celiac trunk was assessed by visual observation in 66 Caucasian dissected bodies comprised of both males $(\mathrm{n}=$ $30)$ and females $(n=36)$. These samples were obtained at the School of Anatomical Sciences, University of the Witwatersrand, Johannesburg. We adapted our findings to the most recent classification system for all variations seen in the configuration of the celiac trunk as in a recent report by Pinal-Garcia et al.

Fig. 1. A schematic diagram representing the 4 major and most common variations of the celiac trunk brunching patterns. (A) True tripod, all 3 branches arise at the terminal aspect of the trunk; (B) false tripod there is a branch arising on the stem of the trunk (LGA) before its terminal portion; (C) splenogastric trunk, the common hepatic artery arising from the abdominal aorta; (D) hepatosplenic trunk, the left gastric artery arising directly from the aorta. CT, celiac trunk; $\mathrm{CHA}$, common hepatic artery; SA, splenic artery; LGA, left gastric artery (Illustration by R Ndou). 
Dissection. A midline incision was made from the xiphoid process of the sternum to the level of the anterior superior iliac spine. Two lateral incisions were then made, one superiorly along the subcostal plane and one more inferiorly, at the level of the anterior superior iliac spine with both lateral incisions ending at the mid-axillary line. These dissections revealed the abdominal cavity and visceral organs of the abdomen. The pancreas and stomach were then dissected and mobilised to view the celiac trunk and its main branches as well as the superior mesenteric artery. The stomach was dissected at the gastroduodenal junction and reflected superiorly, while the pancreas was carefully dissected at the head and reflected laterally and to the left taking special care to preserve the arteries in the immediate vicinity. The branches of the celiac trunk were then traced from their source to termination at their respective visceral organs and the normal pattern and variations of the celiac trunk were photographed and recorded for further analysis.

\section{RESULTS}

Trifurcated celiac trunk. The majority of individuals (84.84\%) exhibited a normal celiac trunk configuration (Type I), and occurred in equal proportions in both males and females (42.52\% Table I). The true tripod or Type I was observed in $46.96 \%$ of the sample, with a lower prevalence in males $21.21 \%$ than females $25.75 \%$ (Table II, Fig. 2a). In contrast, the false tripod or Type II was observed in $37.88 \%$ of the sample, with a higher prevalence in males $(21.21 \%)$ than females $16.67 \%$ ) (Table II, Fig. 2b).

Hepatosplenic and splenogastric trunk. In 2 females, the celiac trunk bifurcated into the common hepatic and splenic arteries forming a hepatosplenic trunk, with the left gastric artery arising from the abdominal aorta (Table
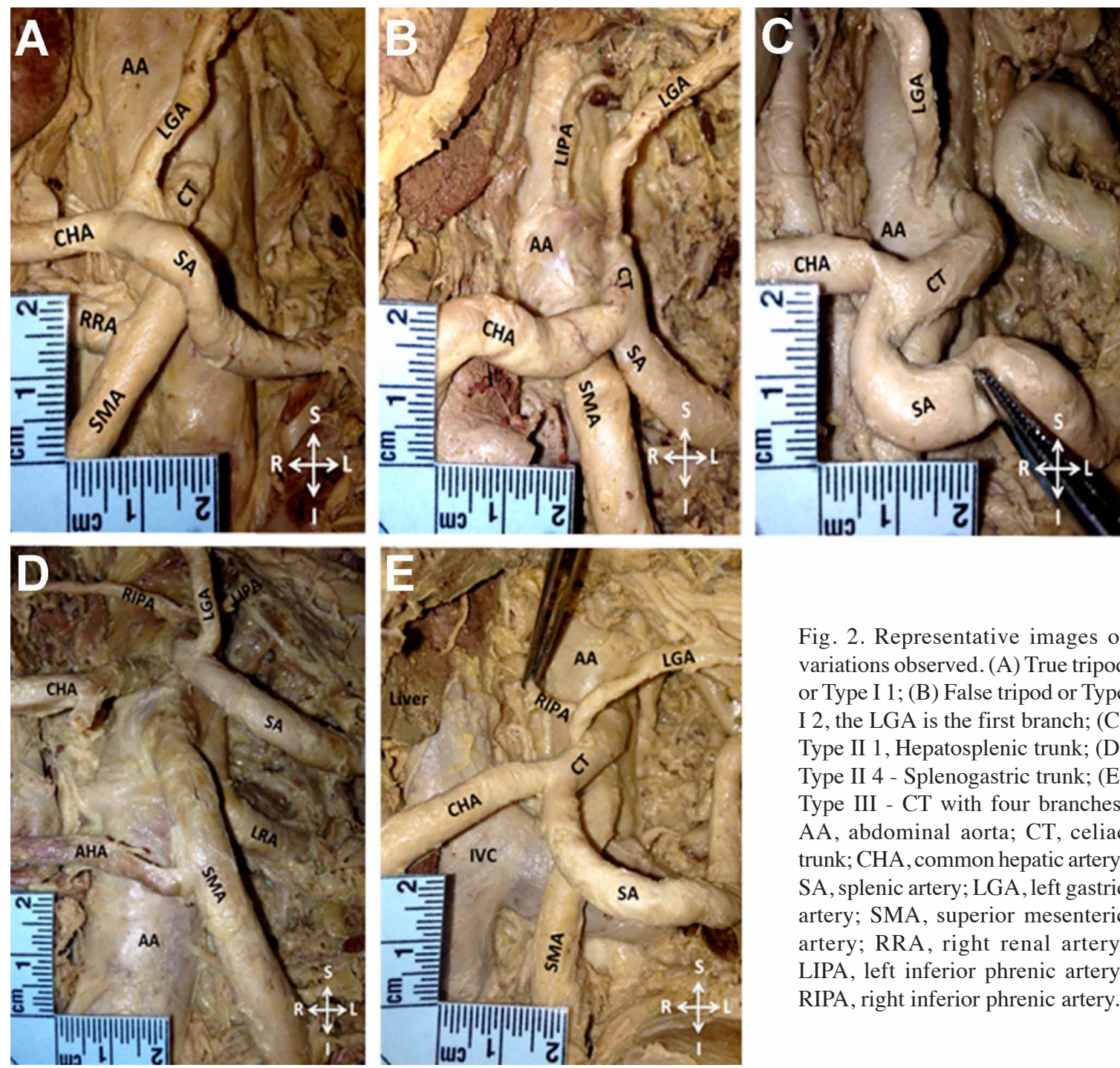

Fig. 2. Representative images of variations observed. (A) True tripod or Type I 1; (B) False tripod or Type I 2, the LGA is the first branch; (C) Type II 1, Hepatosplenic trunk; (D) Type II 4 - Splenogastric trunk; (E) Type III - CT with four branches. AA, abdominal aorta; CT, celiac trunk; CHA, common hepatic artery; SA, splenic artery; LGA, left gastric artery; SMA, superior mesenteric artery; RRA, right renal artery; LIPA, left inferior phrenic artery; RIPA, right inferior phrenic artery. 
II; Fig. 2c). No males exhibited this pattern. In one male, the celiac trunk bifurcated into the left gastric artery and splenic artery forming a splenogastric trunk or Type II 4, with the common hepatic artery arising independently from the abdominal aorta (Table II; Fig. 2d). No female showed this pattern.

Celiac trunk with four branches. The celiac trunk gave off four branches (Type III) in $10.61 \%$ of the specimens. This consisted of 1 male and $6(9.1 \%)$ females (Table II, Fig. 2e). This configuration consisted of a final bifurcation into the common hepatic and splenic arteries, with the third branch always being the left gastric artery and the fourth branch being either the right or left inferior phrenic artery.

\section{Relationship of the celiac trunk and superior mesenteric} artery. All specimens in the study exhibited a celiac trunk arising directly from the abdominal aorta. The common hepatic artery, splenic artery and left gastric artery either arose from the celiac trunk or directly from the abdominal aorta. There were no cases of any of these vessels arising from the superior mesenteric artery. In all specimens, the superior mesenteric artery arose independently from the abdominal aorta.

Table II. Frequency of celiac trunk variations observed. Note that the prevalence of Type I is the sum of Type I 1 Type I 2. CT, Celiac trunk; CHA, common hepatic artery; LGA, Left gastric artery; SA, Splenic artery

\begin{tabular}{lccc}
\hline Variation Type & Male $\mathrm{n}=30$ & Female $\mathrm{n}=36$ & Total $\mathrm{n}=66$ \\
\hline Type I - Trifurcation of the CT into LGA, CHA and SA & $28(42.52 \%)$ & $28(42.42 \%)$ & $56(84.84 \%)$ \\
Type I 1 - true tripod, comm on origin of LGA, CHA and SA & $14(21.21 \%)$ & $17(25.75 \%)$ & $31(46.96 \%)$ \\
Type I 2 - false tripod, the LGA, CHA or SA is the first branch & $14(21.21 \%)$ & $11(16.67 \%)$ & $25(37.88 \%)$ \\
Type II 1 - Hepatosplenic trunk - LGA from AA & $0(0.00 \%)$ & $2(3.03 \%)$ & $2(3.03 \%)$ \\
Type II 4 - Splenogastric trunk; CHA arising from AA & $1(1.52 \%)$ & $0(0.00 \%)$ & $1(1.52 \%)$ \\
Type III - CT with four branches & $1(1.52 \%)$ & $6(9.1 \%)$ & $7(10.61 \%)$ \\
\hline
\end{tabular}

\section{DISCUSSION}

Due to the clinical significance of the celiac trunk and its main branches, knowledge and correct identification of variations in its configuration is a prerequisite for successful abdominal surgery (Wang et al., 2014). The prevalence and types of variation in celiac trunk branches may vary by population. Panagouli et al., summarised the prevalence of celiac trunk variations in different populations worldwide. However, the variations for the South African population was missing in their review as no published data was available at the time. Therefore, we describe the variations of the celiac trunk among South Africans using a cadaveric sample. Since various descriptions exist, and to minimise the possibility of misunderstandings, the latest classification by Panagouli $e t a l$. which was recently adopted by Pinal-Garcia et al., was used in the present study.

The incidence of a normal celiac trunk configuration, namely a trifurcation into the common hepatic, splenic and left gastric arteries, is reported to range from $54 \%$ to 95.9 $\%$ in previous studies (Koops et al.; Chitra, 2010). In the current study, the normal branching pattern of the celiac trunk occurred in $84.84 \%$ of the sample. This is higher than the $75 \%$ reported by, Lipshutz in a predominantly Caucasian cadaveric study done in the United States of America. Greeks are reported to have $90.9 \%$ celiac trunk trifurcation
(Venieratos et al.). Our findings are relatively more similar to the studies that used Caucasians, in contrast to PinalGarcia et al., found a much lower prevalence of $43 \%$, in Maxicans. This indicates that the celiac trunk configuration may be a partly genetically determined trait.

In the current study, celiac trunk trifurcation (Type I) was further subdivided into either a true tripod (Type I 1) or false tripod (Type I 2) as previously explained (Panagouli et $a l$.). Some studies document variations in the celiac trunk configuration but do not classify them separately as either a true tripod or false tripod (Iezzi et al., 2008; Mburu et al., 2010). In the current study the true tripod was found in 46.96 $\%$ of the sample, with the false tripod presenting $37.88 \%$ of the specimens. This finding is aligned with the findings in Greeks with a predominance of the true tripod over the false tripod (74.0 \% vs. $16.9 \%$ ) (Venieratos et al.). However, contrasting findings were made in other studies that report a predominance of the false tripod over the true tripod configuration (Petrella et al., 2007; Higashi et al., 2009).

In the present study, the presence of a fourth branch $(10.6 \%)$ was the second most common variation after the false tripod. The additional fourth branch always presenting as the right or left inferior phrenic artery. This is similar to 
previous reports that found the celiac trunk to give off additional branches (Nayak et al., 2008; Mburu et al.) and in some cases the inferior phrenic arteries being the additional branch in 8 to $10 \%$ of the samples (Petrella et al.).

In $2(3 \%)$ specimens the celiac trunk bifurcated into the common hepatic and splenic arteries, with the left gastric artery arising independently from the abdominal aorta. Previous studies (Chen et al.; Song et al.) report the frequency of a hepatosplenic trunk in $4.3 \%$ and $4.4 \%$ respectively. However, Venieratos et al., did not find this pattern in a Greek sample. The rarest variation of the celiac trunk documented in the current study was that of the celiac trunk bifurcating into the splenic artery and left gastric artery to form a splenogastric trunk. Previous studies have reported bifurcation of the celiac trunk into a splenogastric trunk in $1.2 \%, 1 \%$ and $1.3 \%$ of their studies respectively (Petrella et al.; Chen et al.; Venieratos et al.).

Clinical interest in the origin of celiac trunk and superior mesenteric arteries is well documented (Winston et al., 2007; Song et al.; Wang et al.). The celiac trunk and superior mesenteric artery are the two of the largest arteries to arise from the abdominal aorta and many variations in their origin at the abdominal aorta have been reported (Winston et al.; Song et al.; Wang et al.). In the current study all the celiac trunks and superior mesenteric arteries that were assessed arose independently from the abdominal aorta. This finding is aligned with previous studies that found all celiac trunks and superior mesenteric arteries in their studies to arise independently from the abdominal aorta (Iezzi et al.; Ugurel et al., 2010; Prakash et al.).

Clinical relevance of the celiac trunk and its branches. In liver transplantation cases where the recipient hepatic artery cannot always be used, other celiac trunk branches may be used to provide conduits for liver irrigation. The flow of the recipient hepatic artery needs to be adequate for this vessel to be used. If inadequate flow exists, dissection of the recipient celiac trunk is performed at a distance from the pancreases. Conduits that take a long and often winding pathway, especially passing on the anterior aspect of the pancreases increase the risk of thrombosis. Aorto hepatic conduits are possible but are mostly used in emergency cases to maintain blood supply as they have a higher risk of long term post-surgical thrombosis (Stange et al., 2003).

Pancreaticoduodenectomy is indicated for cholangiocarcinoma and ampullary tumors (Feng et al., 2014). This becomes complicated when there are variations in the hepato-biliary vasculature which usually originates from the celiac trunk. Ye et al. (2017) recently reported a case in which they successfully performed pancreaticoduodenectomy in a cholangiocarcinoma patient without a classic celiac trunk. In this patient, the LGA and SA arose from the abdominal aorta and an accessory LHA arising from the LGA. The CHA arose from the SMA and the common origin was termed the "hepatomaesenteric trunk" (HMT). In this case the preoperative identification of the unusual arterial configuration and its relationship with the tumor was crucial in preventing intraoperative vascular injury and post-surgical complications.

Celiac trunk stenosis is reported in approximately one out of ten patients undergoing pancreaticoduodenectomy (Thompson et al., 1981). The existence of an extensive anastomotic network between the celiac and superior mesenteric arteries renders celiac trunk stenosis asymptomatic in most cases. This anastomosis may occur through branches of the superior and inferior pancreaticoduodenal arteries in the head of the pancreas, or branches of the dorsal pancreatic artery in the body of the pancreas. In rare circumstances, an artery of Buhler linking the two trunks may exist (Rong \& Sindelar, 1987). Liver irrigation through the gastroduodenal artery in celiac trunk stenos has been reported despite the celiac trunk branches appearing to be normal (Soonawalla et al., 2007).

\section{CONCLUSIONS}

In the majority of South Africans, the celiac trunk exhibits trifurcation and the branches are exhibited in a true tripod configuration. Having found fewer variations than reported in other populations suggests than a future study with a larger sample may yield more conclusive results. Also, observing that no branches supplying the liver, spleen and stomach arose from the superior mesenteric artery may need a larger sample to be able to infer the finding to the general South African population.

PILLAY, D.; NISCHK, S. D. \& NDOU, R. Variaciones en la configuración del tronco celíaco en sudafricanos: Relevancia clínica. Int. J. Morphol., 38 (6):1662-1667, 2020.

RESUMEN: El tronco celíaco es la primera rama principal de la parte abdominal de la aorta en el nivel de la duodécima vértebra torácica (T12), con ramas que irrigan el bazo, el hígado y el estómago. Sin embargo a nivel mundial, las ramificaciones del tronco celíaco tienden a variar según la población. En este estudio se investigaron los patrones de ramificación del tronco celíaco en una muestra caucásica sudafricana. El tronco celíaco se analizó mediante observación visual en 66 cuerpos disecados compuestos por hombres $(n=30)$ y mujeres $(n=36)$. Estas muestras se obtuvieron en la Facultad de Ciencias Anatómicas de la Universidad 
de Witwatersrand, Johannesburgo. El tronco celíaco surgió directamente de la parte abdominal de la aorta en todos los casos, sin que ninguno estuviera unido a la arteria mesentérica superior. Se observó trifurcación del tronco celíaco en el 84,84\% de la muestra, aunque en el 10,61 \% se observó un tronco celíaco con cuatro ramas. También se observó bifurcación en las arterias hepática y esplénica común formando un tronco hepatoesplénico (2 mujeres) o en la arteria gástrica izquierda y la arteria esplénica formando un tronco esplenogástrico (1 hombre). Los resultados son comparables con otros estudios en caucásicos que muestran una alta tasa de trifurcación del tronco celíaco (mayor al $75 \%$ ). Nuestra muestra presentó menos variaciones que las reportadas en estudios previos. Por lo tanto, es posible que se requieran estudios más amplios con más muestras en el futuro, para determinar todos los patrones de ramificación del tronco celíaco en la población caucásica sudafricana.

PALABRAS CLAVE: Tronco celíaco; Esplenogástrico; Hepatoesplénico; Parte abdom,inal de la aorta; Mesentérico superior.

\section{REFERENCES}

Chen, H.; Yano, R.; Emura, S. \& Shoumura, S. Anatomic variation of the celiac trunk with special reference to hepatic artery patterns. Ann. Anat., 191(4):399-407, 2009.

Chitra, R. Clinically relevant variations of the coeliac trunk. Singapore Med.J., 51(3):216-9, 2010.

Fahmy, D. \& Sadek, H. A case of absent celiac trunk: case report and review of the literature. Egypt. J. Radiol. Nucl. Med., 46(4):1021-4, 2015.

Feng, J.; Chen, Y. L.; Dong, J. H; Chen, M. Y.; Cai, S. W. \& Huang, Z. Q. Post-pancreaticoduodenectomy hemorrhage: risk factors, managements and outcomes. Hepatobiliary Pancreat. Dis. Int., 13(5):513-22, 2014.

Iezzi, R.; Cotroneo, A. R.; Giancristofaro, D.; Santoro, M. \& Storto, M. L. Multidetector-row CT angiographic imaging of the celiac trunk: anatomy and normal variants. Surg. Radiol. Anat., 30(4):303-10, 2008.

Koops, A., Wojciechowski, B.; Broering, D. C.; Adam, G. \& KrupskiBerdien, G. Anatomic variations of the hepatic arteries in 604 selective celiac and superior mesenteric angiographies. Surg. Radiol. Anat., 26(3):239-44, 2004.

Lipshutz, B. A composite study of the coeliac axis artery. Ann. Surg., 65(2):159-69, 1917.

Mburu, K. S.; Alexander, O. J.; Hassan. S. \& Bernard, N. Variations in the branching pattern of the celiac trunk in a Kenyan population. Int J. Morphol., 28(1):199-204, 2010.

Moore, K.; Dalley, A. \& Agur, A. Clinically Oriented Anatomy. $7^{\text {th }}$ ed. New York, Lippincott Williams \& Wilkins, 2014.

Nayak, S. R.; Prabhu, L. V., Krishnamurthy, A.; Kumar, C. G.; Ramanathan, L. A.; Acharya, A. \& Sinha, A. P. Additional branches of celiac trunk and its clinical significance. Rom. J. Morphol. Embryol., 49(2):247-9, 2008.

Panagouli, E.; Venieratos, D.; Lolis, E. \& Skandalakis, P. Variations in the anatomy of the celiac trunk: A systematic review and clinical implications. Ann. Anat., 195(6):501-11, 2013.

Petrella, S.; de Sousa Rodriguez, C. F.; Sgrott, E. A.; Fernandes, G. J. M.; Marques, S. R. \& Prates, J. C. Anatomy and variations of the celiac trunk. Int. J. Morphol., 25(2):249-57, 2007.

Pinal-Garcia, D. F.; Nuno-Guzman, C. M.; Gonzalez-Gonzalez, M. E. \& Ibarra-Hurtado, T. R. The celiac trunk and its anatomical variations: a cadaveric study. J. Clin. Med.Res., 10(4):321-9, 2018.
Prakash; Rajini, T.; Mokhasi, V.; Geethanjali, B. S.; Sivacharan, P. V. \& Shashirekha, M. Coeliac trunk and its branches: anatomical variations and clinical implications. Singapore Med. J., 53(5):329-31, 2012.

Rong, G. H. \& Sindelar, W. F. Aberrant peripancreatic arterial anatomy. Considerations in performing pancreatectomy for malignant neoplasms. Am. Surg., 53(12):726-9, 1987.

Song, S. Y.; Chung, J. W.; Yin, Y. H.; Jae, H. J.; Kim. H. C.; Jeon, U. B.; Cho, B. H.; So, Y. H. \& Park, J. H. Celiac axis and common hepatic artery variations in 5002 patients: systematic analysis with spiral CT and DSA. Radiology, 255(1):278-88, 2010.

Soonawalla, Z.; Ganeshan, A. \& Friend, P. Celiac artery occlusion encountered during pancreatic resection: a case report. Ann.R. Coll. Surg. Engl., 89(1):W15-7, 2007

Stange, B. J.; Glanemann, M.; Nuessler, N. C.; Settmacher, U.; Steinmüller, T. \& Neuhaus P. Hepatic artery thrombosis after adult liver transplantation. Liver. Transpl., 9(6):612-20, 2003.

Thompson, N. W.; Eckhauser, F. E.; Talpos, G. \& Cho, K. J. Pancreaticoduodenectomy and celiac occlusive disease. Ann. Surg., 193(4):399-406, 1981.

Ugurel, M. S.; Battal, B.; Bozlar, U.; Nural, M. S.; Tasar, M.; Ors, F.; Saglam, M. \& Karademir, I. Anatomical variations of hepatic arterial system, coeliac trunk and renal arteries: an analysis with multidetector CT angiography. Br. J. Radiol., 83(992):661-7, 2010.

Venieratos, D.; Panagouli, E.; Lolis, E.; Tsaraklis, A. \& Skandalakis, P.A morphometric study of the celiac trunk and review of the literature. Clin. Anat., 26(6):741-50, 2013.

Wang, Y.; Cheng, C.; Wang, L.; Li, R.; Chen, J. H. \& Gong, S. G. Anatomical variations in the origins of the celiac axis and the superior mesenteric artery: MDCT angiographic findings and their probable embryological mechanisms. Eur. Radiol., 24(8):1777-84, 2014.

Winston, C. B.; Lee, N. A.; Jarnagin, W. R.; Teitcher, J.; DeMatteo, R. P.; Fong, Y. \& Blumgart, L. H. CT angiography for delineation of celiac and superior mesenteric artery variants in patients undergoing hepatobiliary and pancreatic surgery. AJR Am.J. Roentgenol., 189(1):W13-9, 2007.

Ye, Z.; Ye, S.; Zhou, D.; Zheng, S. \& Wang, W. A rare variation of celiac trunk and hepatic artery complicating pancreaticoduodenectomy. A case report and literature review. Medicine (Baltimore), 96(48):e8969, 2017.

Corresponding author:

Robert Ndou

Department of Anatomy

School of Medicine

Sefako Makgatho Health Sciences University

Ga-Rankuwa

Pretoria, 0204

SOUTH AFRICA

Email: robert.ndou@smu.ac.za

Received: 02-07-2020

Accepted: 10-08-2020 